\title{
The Difference of Anthropometric Growth and Development Velocity Between Lower Classes and Upper Classes Group of Primary School Children
}

\author{
Gano Sumarno, Agus Mahendra*, Bustanil Arifin \\ Department of Sport Education, Faculty of Sport and Health Education \\ Universitas Pendidikan Indonesia \\ Bandung, Indonesia \\ *agus_mahendra@upi.edu
}

\begin{abstract}
This research aim is to compare the anthropometric growth and development of children in primary school, between group of lower classes (1st to 3rd grade) and upper classes (4th to 6th grade), in terms of the speed and magnitude of its changes in stature, circumference and wide. The data is gathered from children's anthropometric measures in the respective grades and the average of its alteration are measured by combining the average score of anthropometric size change both from the lower grade group and the upper grade group. It is estimated that the speed of change depicted the growth pattern in children between the different groups. The measurement of stature, weight, breadth of Biacromial and Bicristal, as well as the circumference of head and limbs is carried out using anthropometric scales. The data have shown that the speed of growth of the upper classes group is faster than the lower classes group. The scrutiny trace to the theory indicated that this tendency is all brought about and influenced by the onset of growth spurt in the period adolescence.
\end{abstract}

Keywords-Anthropometric; growth and development; early childhood

\section{INTRODUCTION}

The issue of students' growth and physical development has been becoming an interesting discussion topic in nowadays discourse. This is especially related to the scarcity of data about the pattern of growth and development of children [1], especially when they enter school age period [2]. This is certainly different from the moment the children at the age of early childhood, because since their born, the pediatricians will regularly take measurements of their growth and development process to a certain age. The frequency and distance of the measurement usually decreases when the age of the children entered the school age and finally stops since they no longer required visiting the pediatrician unless they are sick [3].

In Indonesia, the scarcity of data of children's growth and development in schools is exacerbated by the lack of awareness of parents about the process of growth and development of their children. The majority of parents do not realize that their children growth need to be regularly monitored to find out that their children are normal, abnormal, or affected by certain abnormalities. So, what is happening is: not parents, not also teachers at school. To a certain extent we must even feel apprehensive since the school also never put any concerns in relation to children growth and development. The school has never explicitly give authority to particular teacher, so none of teacher is aware of and knows about the task of measurement.

In a broader context, the problem of not having the authority to monitor and measure the growth and development of children in school can certainly be addressed to the absence of national policy [4]. In brief, duties and authority of teachers in school is to develop an educational program that is also a supporting element of national health movement in schools [5]. In this case, the Ministry of Education and Culture and the Ministry of Health have never synergized to mutually agree to use schools as a health program development agent. Therefore it is also natural that in Indonesia schools, the development of the School Health Program has never received a proper attention [6].

Recognizing this, there needs to be sufficient encouragement to make strategic steps to realize the policy that giving a chance for physical education teacher to have the authority and responsibility [7], to take the initiative in the anthropometric measurement program of elementary school students, in order to obtain data that can be justified regularly by conducting and monitoring the pattern of growth and development of Indonesian children [8]. Then it is expected that status, speed, patterns and normality of the children growth and development can be determined and proactively take necessary steps to anticipate many attributing factors positively and negatively triggering the children growth [9].

Encouraged to make efforts to monitor the health status of elementary school students in Indonesia and see the influence of life and lifestyle of elementary school students on their growth and development, this research was conducted with firstly concentrating on the differences in growth and development of elementary students from lower grades children and upper grades [10]. 


\section{RESEARCH METHOD}

\section{A. Research Approaches and Methods}

Research on these physical characteristics uses a survey and field measurement approach, involving many trained surveyors to conduct anthropometric measurements with relying on cross-sectional data. Cross-sectional is one of the methods to follow the growth process of children, aside the other method called longitudinal and mixed-longitudinal studies. Crosssectional study means that the efforts to conduct the measurement and the status of growth and development of children anthropometrics involved a large number of individuals at each age, and each is represented only once in the sample [11].

\section{B. Research Instrument}

This study has intended to measure the physical characteristics of elementary school children that commonly termed as anthropometric measurement. To measure anthropometric characteristics, a meter-scale instrument as a number of related measuring instruments to measure height, weight, head circumference, shoulder width, pelvic width, sitting height, leg length, upper arm circumference, for circumference, thigh circumference, and calf circumference. In addition, simultaneously, also measured body fat composition (a skin measurement) with a device called a caliper meter.

\section{Research Participants}

Participants in this study were elementary school students from partner schools totaling 5 elementary schools in Bandung, from grades 1 to 6 . The total number of students is 916 , consisting of 456 male students and 460 female students. Those children are anthropometrically measured by teachers and PETE students who were previously involved in the anthropometric measurement training program, which lasted about 2 days of training.

\section{RESUlTS AND DisCUSSION}

\section{A. Results}

The results of this study are divided into three parts of measurement results groups, each of which represent a group of sizes from different bodies. The three groups are (1) the length of the body segment that will determine body height or sitting height and leg length including body size, (2) body segment width groups such as shoulder width, pelvic width, elbow width, and knee width that will determine the size of the body frame in terms of volume, and (3) the circumference of the body segments such as head, upper arm, forearm, thigh and calf circumference, which also determine the muscle volume around the skeleton.

Those results are as the followings:

1) Size of stature and weight: In terms of body stature and weight, there are at least four segments of the body that are measured, they are stature or height of the body while in the standing position, weight of the body as the representative of body mass of each individual, sitting height that are measured

while a child is in sitting position, and length of the leg that are measured from the iliac crests of pelvic bone crosses along the leg to the inner bone of ankle (tarsal). Each of this segments provided a bit of information from the data average as the followings:

TABLE I.

\section{THE DIFFERENCE SIZE OF STATURE AND WEIGHT}

\begin{tabular}{|c|l|c|}
\hline Factor/Grades & \multicolumn{1}{|c|}{ Lower Grades } & Upper Grades \\
\hline Stature & 9.9626394 & 7.603445021 \\
\hline Body Weight & 3.92888058 & 6.413846154 \\
\hline Sitting Height & 5.003839332 & 5.790649262 \\
\hline Leg Length & 6.81529791 & 8.478138255 \\
\hline Total & 25.71065722 & 28.28607869 \\
\hline
\end{tabular}

In form of figure 1 , the difference can be seen as the followings:

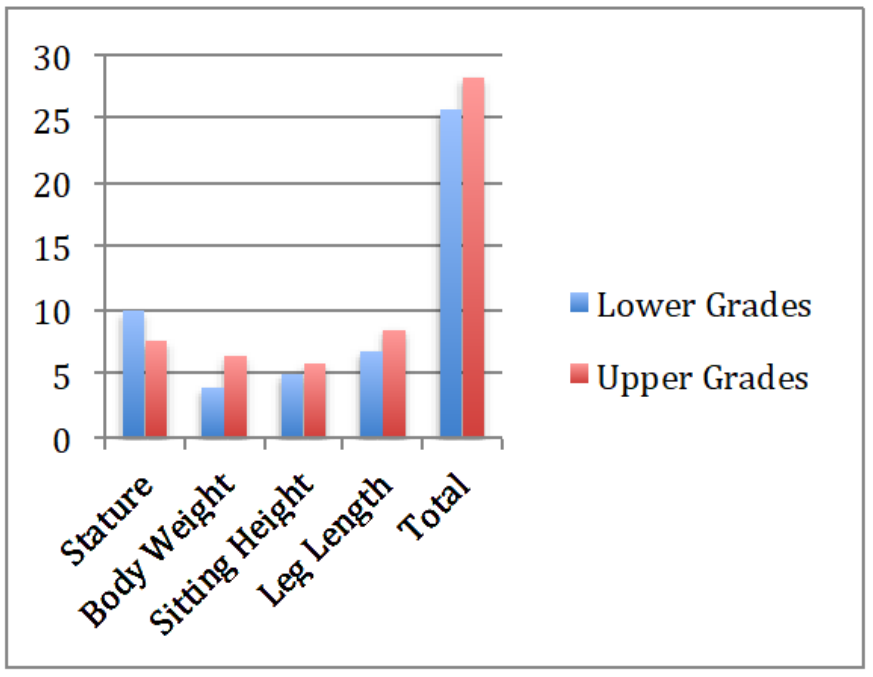

Fig. 1. The difference of size of stature and weight.

In terms of body segments, it can be concluded that in overall the pattern of growth velocity of body height and weight is faster in the upper grade. But separately, the speed and distance of the growth of the height (stature) of the children is faster in the lower classes. On the other three segments, the greater magnitude of the distance was more favoring the upper grades. In terms of weight, the distance between the lower class and the upper class difference seems quite striking; the lower class is only 3, 92, while the upper class is more than 6.41. On the other hand, the difference in distance of sitting height between lower and upper classes is almost imperceptible, namely from 5.0 to 5.79. As for the size of the leg length the difference started to steepen back, where the lower class reaches 6.81, and at the upper class reaches 8.47 .

2) Size of body breadth: In terms of the breadth of body, there are at only two body segments that are measured, they are shoulder breadth which is commonly called as biacromial breadth and hip or pelvic breadth that is commonly called as bicristal breadth. These two body segments are the most important thing to measure the volume of body strength, since its size will also reflect the size of the posture. 
TABLE II. THE DIFFERENCE SIZE OF BODY BREADTH

\begin{tabular}{|c|l|c|}
\hline Factor/Grade & Lower Classes & Upper Classes \\
\hline Shoulder Breadth & 0.586768405 & 4.752156466 \\
\hline Pelvic Breadth & 0.388572611 & 1.341888333 \\
\hline Total & 0.975341016 & 6.094044799 \\
\hline
\end{tabular}

In form of figure 2, the difference can be seen as the followings:

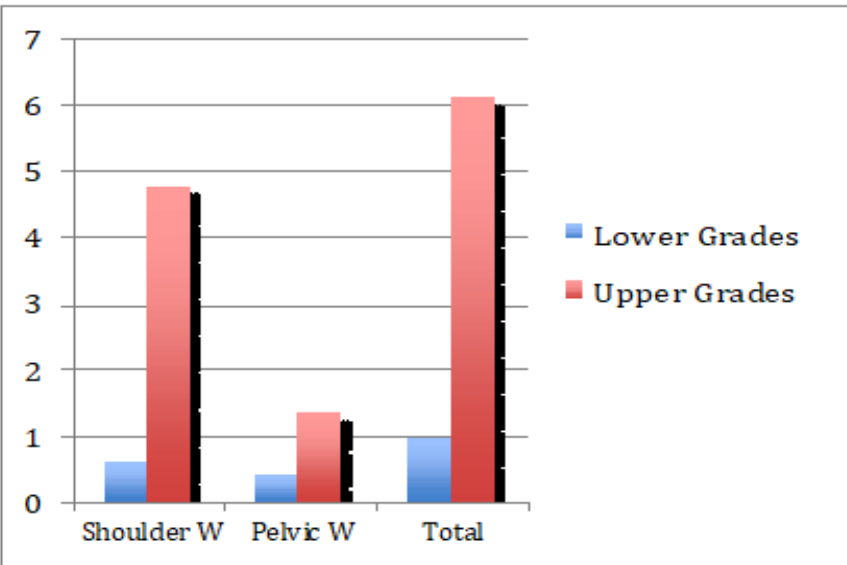

Fig. 2. The difference size of body breadth

The anthropometric size associated with the width of the body segment indicates the same favor as length and weight, only with different magnitudes. The lower grade children seemed to suffer from the lack of growth in bicristal and biacromial since their growth are far less in terms of the magnitude. It could be inferred that at the ages of grade 1, grade 2, and grade 3, the growth and development of these two segments are relatively slower or less severe than students of the upper classes. The differences between them are noticeable because they vary up to several digits. For example the shoulder width of the lower classes group only reaches 0.568 while in the upper classes group reaches 4.75. At the width of the pelvic, the development of both group is indeed not too much different; while the lower classes group reached 0.388 digits, on the other hands, the group of upper classes reached 1.34 digit. When the two segments average are combined, it was not surprising that the difference between the two group were striking and become very steep, with the lower classes only reached 0.975 , while the upper classes reached almost digit of 7.00 .

3) Size of body circumferences: There are five body segments in the area of body circumferences; they are head, upper arm, lower arm, thigh, and calf circumferences. The data shown the following tendencies:

TABLE III. THE DIFFERENCE SIZE OF BODY CIRCUMFERENCES

\begin{tabular}{|c|l|l|}
\hline Factor/Grades & \multicolumn{1}{|c|}{ Lower Grades } & \multicolumn{1}{|c|}{ Upper Grades } \\
\hline Head Circumference & 0.811584703 & 1.202141847 \\
\hline Upper Arm Circumference & 0.505492269 & 2.076391097 \\
\hline Lower Arm Circumference & 0.99371034 & 1.422498815 \\
\hline Thigh Circumference & 3.199828244 & 4.470025292 \\
\hline Calf Circumference & 1.940096206 & 4.901869159 \\
\hline Total & 7.450711761 & 14.0729262 \\
\hline
\end{tabular}

In form of figure 3, the difference can be seen as the followings:

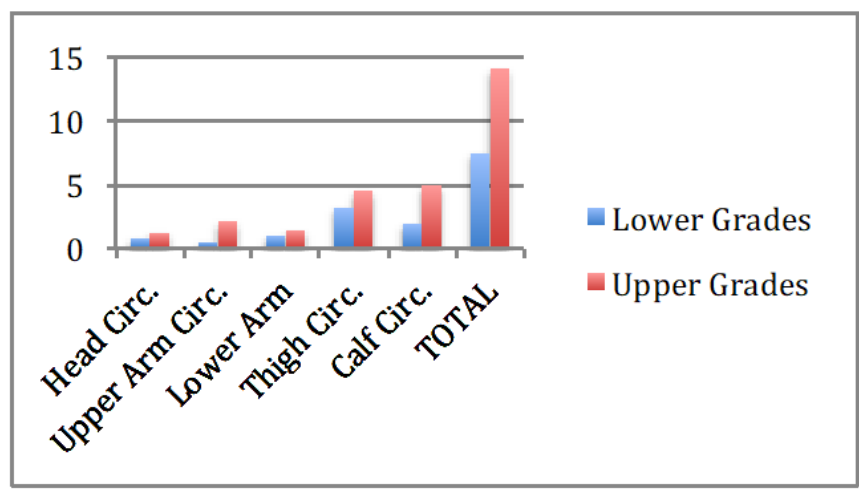

Fig. 3. The difference Size of body circumference

From the data shown and the figure 3 above, it was indicating that the circumference changes that occur in each segment of the body moved in a slow rate. Head circumference for example, changed very little during this period of lives, only ranged below 2 centimeters. Likewise in the difference changes between the group of lower grades and upper grades, which was not really obvious. The lower class is at 0.81 , while the higher class is at 1.20; different but in a very minor difference. That kind of little change also occurred in the upper arm circumference, it only differs around 1.5 digits between the lower classes and the upper classes. Not to mention the forearm circumference, it also has a minor difference, one is only in the range of 0.99 , while the other is in the range of 1.42 .

The bigger difference started to be more obvious in the thigh circumference and calf circumferences, where the lower class of the thigh circumference shows the digit of 3.19 and in the higher classes touched the digit of 4.47; and in the calf circumference, the lower classes reached 1.94 while the upper grades up high to digit of 4.90 . So, it was concluded, that the big overall differences among all classes from grade 1 to grade 6 most of all are contribute by the last two segments, they are from thigh and calf circumferences combined altogether, namely between 7.45 for the lower grades and 14.92 for the upper grades; adrift around 6.62 points.

\section{B. Discussion}

What can we understand from the data above? The answer is, we can learn that the age period of children has different stages, patterns, velocities, and also variants of the onset and outset in the growth and development. For instant, growth and development of physical and anthropometric move more slowly at the age of children when they are in early childhood, and move away rising at later ages, especially when approaching growth spurts.

This fact gives an indication that the law and the theory of growth and development in lower class children is true, that in elementary school grades 1,2 and 3, periods of physical growth are slowing down. However, this must be related to the law and the principle of motor learning stating that "when children's physical growth and development are slowing down, the learning capacity to movement and skill are at very rapid 
rate." Conversely, when children arrive at the state of their maximum rate at their physical growth and development, the learning capacity on motor skills is also slowing down. So, this law works and occurs in the opposite direction, and it all provides a precious signal and precaution to teachers and all educators to put a wise and prudent consideration to apply in the learning process.

It does mean that the learning of motor skills and all movements' tasks are very critical for the children in the lower grades period, and that all children of their ages are at their critical moment to learn and experience rich and meaningful movement tasks and all bodily experiences, encompassing the other period of their growth and development in their lives. For that reason, all teachers must have this kind of knowledge related to children stages of growth and development, in order for them to plan and entertain the most appropriate level of difficulty and its underlying emphasis to be provided to children at every stage of children lives.

\section{CONCLUSIONS}

The results of this study suggested that the speed of growth of the upper classes group is faster than the lower classes group. This is in accordance with the theory stating the same thing and that this tendency is all brought about and influenced by the onset of growth spurt in the period adolescence. The speed of the growth and development of most parts of the body will depend and partially affected by the hormonal process happening in the body of the children in the upper group, then influence the velocity on the changes in bones and muscle tissues.

This knowledge suggested that parents and teachers need to consider this tendency in order to foster the children's growth and development for the purpose of optimizing the children growth and development and also of fostering learning, especially in physical education lesson. For parents, it is important that their children be supported by the right and appropriate menus of foods while they are growing, and it also suggested to only provide children with the balance diet while in their critical age, combined with the habitual process for their children preferences in food. And for Physical Education teachers, this tendency should be carefully considered in terms of what and how much movement task should be designed and what kind of learning environment should be situated or created in giving a meaningful learning situation. There should be strongly believed by the teachers, that, when children are in their fastest rate of growth, it is important that children be provided with meaningful experiences in moving, and when children are in their slower rate of growth, they need to be directed with the right dose of exercises intensity for their growth. Of course, a further study needs to be conducted in other aspect of implementation, to elicit a stronger evidence of its influences.

\section{ACKNOWLEDGEMENT}

The research team acknowledged that there were a large number of participants involved in this study for whom we really indebted. They are mostly PE teachers from the elementary schools that the data were withdrawn. On this occasion, we would like to express our great gratitude for their contribution and hoping that the cooperation that was established could be further sustained and continued in other schedule of research.

\section{REFERENCES}

[1] V. Povilaitis and K. A. Tamminen, "Delivering Positive Youth Development at a Residential Summer Sport Camp. Journal of Adolescent Research, vol. 33, no. 4, pp. 470-495,2018.

[2] M. L. George and M. D. Curtner-Smith, "Influence of middle school pupils' acculturation on their readings of and expectations for physical education," Asia-Pacific Journal of Health, Sport and Physical Education, vol. 7, no. 2, pp. 191-203, 2016.

[3] S. B. Young, "Movement is fun: An occupational therapy perspective on a program for preschoolers," Occupational Therapy in Health Care, vol. 4, no. 2, pp. 37-46, 1987.

[4] M. Y. Y. Yamamoto, "Development of the sporting nation: Sport as strategic area of national policy in Japan," International Journal of Sport Policy, vol. 4, no. 2, pp. 277-296, 2012.

[5] A. Hargreaves, "The perceived value of Health Education in schools: New Zealand secondary teachers' perceptions. Journal of Curriculum Studies, vol. 45, no. 4, pp. 560-582, 2013.

[6] J. F. Governali, B. C. Hodges, and D. M. Videto, "Health Education and Behavior: Are School Health Educators in Denial?," American Journal of Health Education, vol. 36, no. 4, pp. 210-214, 2005.

[7] T. J. Newman, M. Kim, A. R. Tucker and M. A. G. Alvarez, "Learning through the adventure of youth sport," Physical Education and Sport Pedagogy, vol. 23, no. 3, pp. 280-293, 2018.

[8] F. E. Holway and L. L. Spriet, "Sport-specific nutrition: Practical strategies for team sports," Journal of Sports Sciences, 29(SUPPL. 1) 37-41. https://doi.org/10.1080/02640414.2011.605459

[9] H. T. Douda, A. G. Toubekis, A. A. Avloniti and S. P. Tokmakidis, "Physiological and anthropometric determinants of rhythmic gymnastics performance. International Journal of Sports Physiology and Performance, vol. 3, no. 1, pp. 41-54, 2008.

[10] V. G. Đorđić, T. Tubić and D. Jakšić, "The Relationship between Physical, Motor, and Intellectual Development of Preschool Children," Procedia - Social and Behavioral Sciences,vol. 233(May), pp. 3-7, 2016.

[11] R. M. Malina and Bouchard Claude, Growth, Maturation, and Physical Activity. Champign IL. Human Kinetics, 1991. 